\title{
Identical Twins with Idiopathic Normal Pressure Hydrocephalus
}

\author{
Andreas Eleftheriou ${ }^{1 *}$ and Fredrik Lundin ${ }^{1}$
}

${ }^{1}$ Department of Neurology, University Hospital, Linköping, Sweden and Department of Clinical and Experimental Medicine, University Hospital, Linköping, Sweden

\begin{abstract}
Background: The pathogenesis of iNPH is inadequately known. Small vessel disease seems to play an important role but the link to a disturbed CSF dynamic is not described. The familial presentation of idiopathic normal pressure hydrocephalus is extremely rare. Nonetheless, the last years the disclosure of familial occurrence seems to be of interest. The increasing reports on familial iNPH indicate a potential genetic component. Except from iNPH and secondary NPH a third form of $\mathrm{NPH}$, familial $\mathrm{NPH}$, is being widely recognized.
\end{abstract}

Case Presentation: We report iNPH in two adult identical twins.

Conclusion: Our case in addition with results from other manuscripts reinforces the suspicion of familial NPH.

Key words: Identical twins; Idiopathic normal pressure hydrocephalus; Familial NPH

\begin{abstract}
Abbreviations: NPH: Normal Pressure Hydrocephalus; CSF: Cerebrospinal Fluid; HC: Hydrocephalus; iNPH: Idiopathic Normal Pressure Hydrocephalus; sNPH: Secondary Normal Pressure Hydrocephalus; MMSE: Mini Mental State Examination; NCSE: Neurobehavioral Cognitive Status Examination; MRI: Magnetic Resonance Imaging; Rout: Resistance to Outflow; kPa: Kilopascal; NFp: Neurofilament Protein; AD: Alzheimer's Disease; FTD: Frontotemporal Dementia; FLTD: Frontotemporal Lobar Degeneration; APOE: Apolipoprotein E; fNPH: Familial Normal Pressure Hydrocephalus.
\end{abstract}

\section{Introduction}

Normal pressure hydrocephalus (NPH) is a clinical syndrome with symptoms of gait unsteadiness, urinary disturbance, and cognition impairment in the context of ventriculomegaly out of proportion of cerebral atrophy and normal cerebrospinal fluid (CSF) pressure [1,2]. Hydrocephalus (HC) is divided into non-communicating $\mathrm{HC}$ and communicating HC. Communicating $\mathrm{HC}$ can be further divided, to idiopathic Normal Pressure Hydrocephalus (iNPH) [3], where no known cause can be found, as opposed to secondary NPH (sNPH) where a known cause lies behind such as a subarachnoid hemorrhage, bacterial meningitis, head trauma or intracranial surgery. The causes and pathophysiological mechanisms are still poorly understood [4]. Comorbidity is an important factor in the prognosis and post-operative outcome of shunt surgery for iNPH [5]. Cardiovascular risk factors and subsequent vascular disease may contribute to the development of iNPH [6-8]. INPH is considered sporadic but there are data of familial clusters of iNPH suggesting at least some kind of genetic influence or propensity for developing iNPH $[9,10]$. The first adult familial NPH case was reported in 1984 by Portonoy, et al. [11] and recently by Cusimano, et al. [12], Takahashi, et al. [13], Mc Girr and Cusimano [14] and Liouta, et al. [15]. Familial cases of congenital hydrocephalus have often been reported and may result from distinct monogenic disorders or may be multifactorial determined [16]. We report iNPH in two adult identical twins.

\section{Case Presentations}

\section{Case I}

A 73-year-old woman with chronic obstructive pulmonary disease, without any other significant medical problems. Her relatives had noticed personality changing in the last few years. At the age of 71 she developed gait disturbance. She felt initially that she was unsteady and after a while she began to walk with a cane. Walking difficulties were accentuated and she became more dependent on a cane or walker in a period of one year. She also experienced worse memory and daytime fatigue and she also described frequent urination than before. Neurological examination assessment showed gait disturbance and cognitive impairment, Mini Mental State Examination (MMSE) 26/30. Neurobehavioral Cognitive Status Examination (NCSE) revealed mild impairment of design capacity. On Magnetic Resonance Imaging (MRI) of the brain there was an enlargement of the ventricles (Evans' index: 0.38, third ventricle, measuring approximately $13 \mathrm{~mm}$ ) with a narrowing of the subarachnoid space and cortical sulci at the high convexity of the cerebrum (Figure 1) which is consistent with the reported features of MRI in iNPH [17,18]. Lumbar CSF-pressure was 90 $\mathrm{mmH}_{2} \mathrm{O}$ and the CSF was acellular with normal amounts of glucose and protein. CSF-neurodegenerative markers were normal, with Tau at 180 $\mathrm{ng} / \mathrm{L}$, beta-Amyloid at $580 \mathrm{ng} / \mathrm{L}$, Fosfo-Tau at $26 \mathrm{ng} / \mathrm{L}$ and NFp at 570 $\mathrm{ng} / \mathrm{L}$. Infusion test showed a start pressure of $9 \mathrm{kPa}$ and resistance to CSF outflow (Rout) at $8.7 \mathrm{kPa}$. There was a marked, transient improvement in gait for several hours after a spinal tap-test and a ventriculoperitoneal shunt was placed. There was an initial improvement 3 month after surgery. At the age of 77 died from malign melanoma with metastases in the lungs.

\section{Case II}

A 75-year-old woman, with a medical history of surgery for atoxic multinodular struma, mild mitral valve insufficiency and a previous heart infarction referred to the neurology department because of unsteady and staggering gait for two years. She also described cognitive decline and a urination urgency but not incontinence. Brain MRI showed an enlargement of the ventricles (Evans index :0.38, third ventricle, measuring approximately $12 \mathrm{~mm}$ ) with a narrowing of the subarachnoid space and cortical sulci at the high convexity of the cerebrum which is consistent with the reported features of MRI in

*Corresponding author: Andreas Eleftheriou, Department of Neurology University Hospital, Linköping, Sweden and Department of Clinical and Experimental Medicine, University Hospital, Linköping, Sweden, Tel: 46733993945; Fax: 46101032668; E-mail: andelef2002@yahoo.gr

Received June 04, 2018; Accepted June 26, 2018; Published June 29, 2018

Citation: Eleftheriou A, Lundin F (2018) Identical Twins with Idiopathic Normal Pressure Hydrocephalus. J Neurol Disord 6: 384. doi:10.4172/2329-6895.1000384

Copyright: (c) 2018 Eleftheriou A, et al. This is an open-access article distributed under the terms of the Creative Commons Attribution License, which permits unrestricted use, distribution, and reproduction in any medium, provided the original author and source are credited. 
Citation: Eleftheriou A, Lundin F (2018) Identical Twins with Idiopathic Normal Pressure Hydrocephalus. J Neurol Disord 6: 384. doi:10.4172/23296895.1000384

Page 2 of 4

iNPH (Figure 1). Neurological examination showed gait disturbance and cognitive impairment (MMSE 27/30). The patient was diagnosed as having iNPH and a ventriculoperitoneal shunt operation was performed. There was an improvement 3 month after surgery but at the 12-months post-operative control she was worse at the motor tests and further results indicated a shunt dysfunction why she subsequently
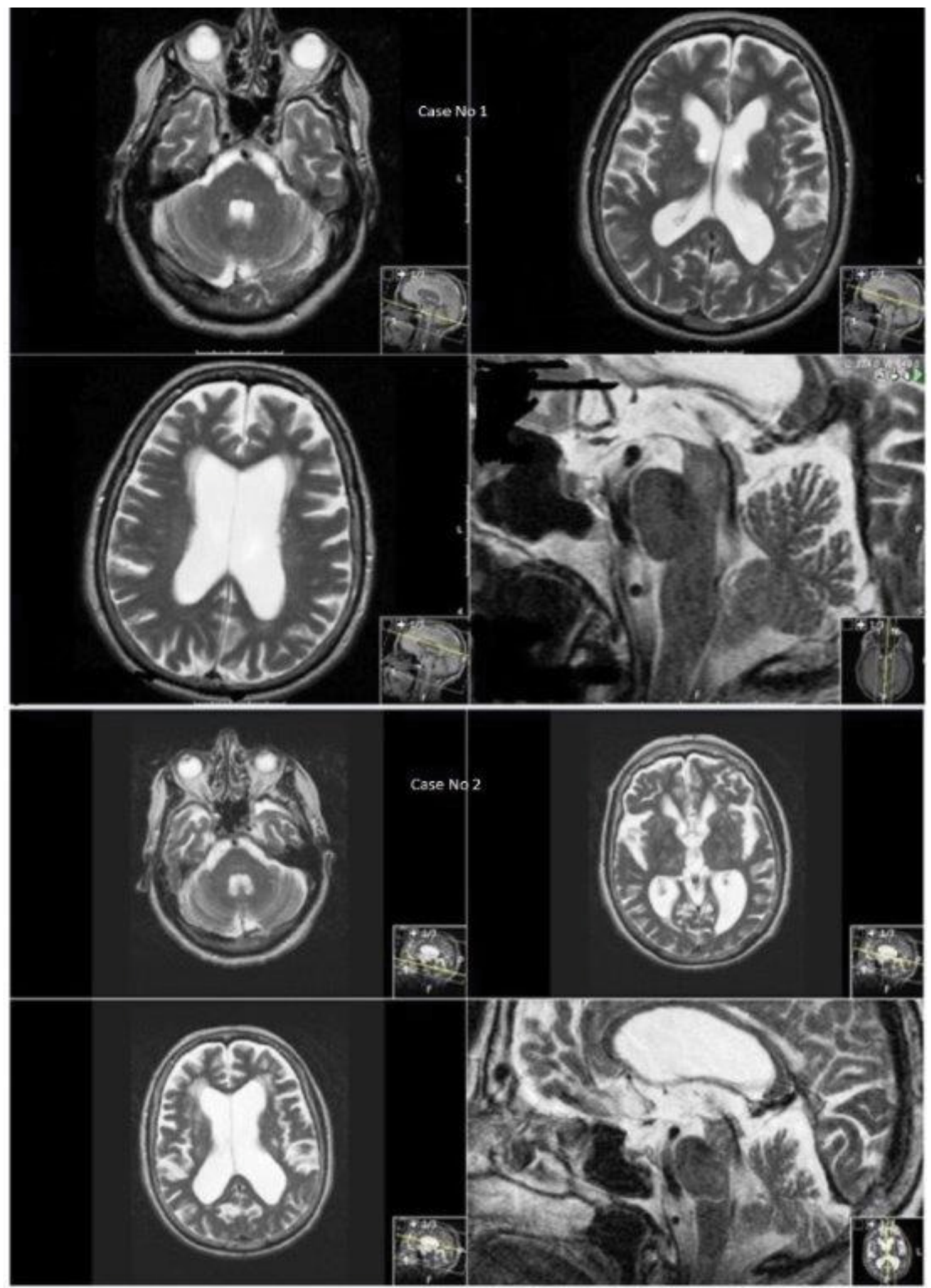

Figure 1: MRI showed an enlargement of the ventricles (Evans' index: 0.38 , third ventricle, measuring approximately $13 \mathrm{~mm}$ ) with a narrowing of the subarachnoid space and cortical sulci at the high convexity of the cerebrum. 
Citation: Eleftheriou A, Lundin F (2018) Identical Twins with Idiopathic Normal Pressure Hydrocephalus. J Neurol Disord 6: 384. doi:10.4172/23296895.1000384

Page 3 of 4

underwent a shunt revision with good results. At the age of 82 she had an ischemic stroke with a left sided hemiparesis and dysarthria.

\section{Discussion}

A thorough explanation of the pathogenesis of iNPH is yet to be presented but some clues are known. Small vessel disease is a risk factor and seems to play an important role but the link to a disturbed CSFdynamics is not described [8]. As in many diseases there may be several different pathways in the pathogenesis and it is likely that iNPH in the future can be divided in different kind of NPH. The most common neuropathologies in patients with iNPH are vascular and AD-related changes [19]. Amyloid plaque has been reported in brain biopsies from patients with iNPH and proposed as a significant feature of the pathology. In iNPH patients the rate of amyloid deposition is higher than in cognitively normal elderly subjects, but no differences in the probability of the apoE4 carriers observed [20]. Presence of apolipoprotein E \&4 (APOE \&4) allele is associated with increased risk of AD. The APOE distribution did not differ significantly between the iNPH patients and control population [21]. Besides small vascular disease Alzheimer's disease (AD) coexists frequently [5]. Frontotemporal dementia (FTD) has been also listed as a comorbidity in iNPH [22].

$\mathrm{AD}$ and FTD has a clear genetic component in their pathogenesis. In literature it is described a patient with C9ORF72 expansionassociated behavioural variant frontotemporal dementia with gait disturbance and ventriculomegaly whose gait score increased after a ventriculoperitoneal shunt insertion [23]. Prevalence of the C9ORF72 expansion in Finnish NPH-register reported as greater than expected. Hence, there may also be a possible connection between FTLD and iNPH. This raises the question of an unknown genetic factor which can activate the mechanism for the development of the disturbed CSFdynamics in iNPH.

A further indication of a genetic background in iNPH raises through a Japanese study where a genome-wide screening for copy number loss of the SFMBT1 gene was performed in patients with iNPH and asymptomatic ventriculomegaly, where a segmental copy number loss of the SFMBT1 gene was found [24]. A segmental copy number loss in intron 2 of the gene in the SFMBT1 gene in patients with shuntresponsive definite iNPH was more frequent than in healthy elderly and PD patients [10]. However, in another study, among Finnish iNPH patients, the copy number loss within intron 2 of SFMBT1 was less prevalent $[25,10]$. The prevalence of the copy number in the SFMBT1 gene was determined to be $11 \%$ in Finnish iNPH-patients and 21\% in Norwegian iNPH patients compared to $37 \%$ in Finnish controls [26].

The identical twins experienced the classic symptoms of iNPH at approximately the same age. The radiological examinations were typical for iNPH and they had no abnormality of CSF and no known cause of secondary NPH, thus they fulfilled the currently accepted clinical and laboratory criteria for the diagnosis of idiopathic normal pressure hydrocephalus also becoming markedly improved after institution of the ventriculoperitoneal shunt. Both patients had normal results for neurodegenerative markers for dementia, Alzheimer's disease and frontal lobe atrophy. Unfortunately, one of the twins has passed away and we have therefore not the possibility to see if they carry the same ApoE genotype and SFMBT1 gene. The increasing reports on familial iNPH indicate a potential genetic component. Except from iNPH and $\mathrm{sNPH}$ a third form of $\mathrm{NPH}$, familial NPH ( $\mathrm{fNPH}$ ) is being widely recognized. Our case reinforces the suspicion of $\mathrm{ANPH}$.

\section{Conclusion}

Although a genetic predisposition for iNPH is proposed further studies are needed to approve the heritability of iNPH. This is of high importance, as the number of familial NPH cases has increased over recent years. It is important to make DNA analysis in future familial cases of iNPH.

\section{Consent for Publication}

The authors have the written consent to publish this case from the patient who is still in life. She gave her consent to use data for her sister on target to improve iNPH investigation and therapy in the future.

\section{Availability of Data and Material}

We used the data from our Cambio COSMIC Healthcare System, which is a digital comprehensive healthcare system installed in all clinics in our region. Radiological material obtained through Sectra Image Display System 7.

\section{Authors' Contributions}

Fredrik Lundin and Andreas Eleftheriou were the neurologists who performed the neurological investigation. Andreas Eleftheriou was the major contributor in writing the manuscript.

\section{Acknowledgements}

Thanks to physiotherapist Johanna Rydja and occupational therapist Katarina Owen for their assessments of motor and cognitive function, respectively.

\section{References}

1. Marmarou A, Young HF, Aygok GA, Sawauchi S, Tsuji O, et al. (2005) Diagnosis and management of idiopathic normal-pressure hydrocephalus: A prospective study in 151 patients. J Neurosurg 102: 987-997.

2. Hakim S, Adams RD (1965) The special clinical problem of symptomatic hydrocephalus with normal cerebrospinal fluid pressure. Observations on cerebrospinal fluid hydrodynamics. J Neurol Sci 2: 307-327.

3. Shenkin HA, Greenberg JO, Grossman CB (1975) Ventricular size after shunting for idiopathic normal pressure hydrocephalus. J Neurol Neurosurg Psychiatry 38: 833-837.

4. Hamlat A, Adn M, Sid-ahmed S, Askar B, Pasqualini E (2006) Theoretica considerations on the pathophysiology of normal pressure hydrocephalus (NPH) and NPH-related dementia. Med Hypotheses 67: 115-123.

5. Malm J, Graff-Radford NR, Ishikawa M, Kristensen B, Leinonen V, et al. (2013) Influence of comorbidities in idiopathic normal pressure hydrocephalus: Research and clinical care. A report of the ISHCSF task force on comorbidities in INPH. Fluids Barriers CNS 10: 22.

6. Kato T, Sato H, Emi M, Seino T, Arawaka S, et al. (2011) Segmental copy number loss of SFMBT1 gene in elderly individuals with ventriculomegaly: A community-based study. Intern Med 50: 297-303.

7. Krauss JK, Regel JP, Vach W, Droste DW, Borremans JJ, et al. (1996) Vascular risk factors and arteriosclerotic disease in idiopathic normal-pressure hydrocephalus of the elderly. Stroke 27: $24-29$.

8. Israelsson H Carlberg B, Wikkelsö C, Laurell K, Kahlon B et al (2017) Vascula risk factors in INPH: A prospective case-control study (the INPH-CRasH study). Neurology 88: 577-585

9. Huovinen J, Kastinen S, Komulainen S, Oinas M, Avellan C, et al. (2016) Familial idiopathic normal pressure hydrocephalus. J Neurol Sci 368: 11-18.

10. Sato H, Takahashi Y, Kimihira L, Iseki C, Kato H, et al. (2016) A segmental copy number loss of the SFMBT1 gene is a genetic risk for shunt-responsive, idiopathic Normal Pressure Hydrocephalus (iNPH): A case-control study. PLoS One 11: e0166615

11. Portenoy RK, Berger A, Gross E (1984) Familial occurrence of idiopathic normal-pressure hydrocephalus. Arch Neurol 41: 335-337.

12. Cusimano MD, Rewilak D, Stuss DT, Barrera-Martinez JC, Salehi F, et al. (2011) Normal-pressure hydrocephalus: Is there a genetic predisposition? Can J Neurol Sci 38: 274-281. 
Citation: Eleftheriou A, Lundin F (2018) Identical Twins with Idiopathic Normal Pressure Hydrocephalus. J Neurol Disord 6: 384. doi:10.4172/23296895.1000384

13. Takahashi $Y$, Kawanami T, Nagasawa H, Iseki C, Hanyu H, et al. (2013) Familial normal pressure hydrocephalus (NPH) with an autosomal-dominant inheritance: A novel subgroup of NPH. J Neurol Sci 308: 149-151.

14. Mc Girr A, Cusimano MD (2012) Familial aggregation of idiopathic normal pressure hydrocephalus: Novel familial case and a family study of the NPH triad in an iNPH patient cohort. J Neurol Sci 321: 82-88.

15. Liouta E, Liakos F, Koutsarnakis C, Katsaros V, Stranjalis G, et al. (2014) Novel case of familial normal pressure hydrocephalus. Psychiatry Clin Neurosci 68: 583-584.

16. Chalmers RM, Andreae L, Wood NW, Raj RVKD, Casey ATH, et al. (1999) Familial hydrocephalus. J Neurol Neurosurg Psychiatry 67: 410-411.

17. Gallia GL, Rigamonti D, Williams MA (2006) The diagnosis and treatment of idiopathic normal pressure hydrocephalus. Nat Clin Pract Neurol 2: 375-381.

18. Kitagaki H, Mori E, Ishii K, Yamaji S, Hirono N, et al. (1998) CSF spaces in idiopathic normal pressure hydrocephalus: Morphology and volumetry. AJNR Am J Neuroradiol 19: 1277-1284.

19. Leinonen V, Koivisto AM, Savolainen S, Rummukainen J, Sutela A, et al. (2012) Post-mortem findings in 10 patients with presumed normal-pressure hydrocephalus and review of the literature. Neuropathol Appl Neurobiol 38: 72-86.

20. Bundo M, Nakamura A, Kato T, Niida S, Iwata K, et al. (2015) Amyloid Deposition and ApoE4 Carriers in Idiopathic Normal Pressure Hydrocephalus. Fluids and Barriers of the CNS 12.Suppl 1: 5.
21. Yang $Y$, Tullberg $M$, Mehlig $K$, Rosengren $A$, Torén $K$, et al. (2016) The APOE genotype in idiopathic normal pressure hydrocephalus. PLoS One 11: e0158985.

22. Relkin N, Marmarou A, Klinge P, Bergsneider M, Black PM, et al. (2005) Diagnosing idiopathic normal-pressure hydrocephalus. Neurosurgery57: S2-4-16.

23. Korhonen VE, Solje E, Suhonen NM, Rauramaa T, Vanninen R, et al. (2017) Frontotemporal dementia as a comorbidity to idiopathic normal pressure hydrocephalus (iNPH): A short review of literature and an unusual case. Fluids Barriers CNS 14: 10

24. Kato T, Iseki C, Takahashi Y, Wada M, Kawanami T, et al. (2010) iNPH (Idiopathic normal pressure hydrocephalus) and AVIM (asymptomatic ventriculomegaly with features of iNPH on MRI). Rinsho Shinkeigaku 50: 963-965.

25. Huovinen $\mathrm{J}$ (2017) The copy number loss in the intron two of the SFMBT1 among Finnish INPH-patients and families, Hydrocephalus 2017, the Ninth Annual Meeting of the International Society for Hydrocephalus and CSF disorders (Hydrocephalus Society).

26. Korhonen $V$ (2017) The copy number loss in the intron two of the SFMBT1 among Finnish INPH-patients and families, Hydrocephalus 2017, the Ninth Annual Meeting of the International Society for Hydrocephalus and CSF disorders (Hydrocephalus Society). 